\title{
Modelagem da linguagem e do contexto na teoria sistêmico-funcional
}

\author{
Adriana Silvina PAGANO (D) \\ Universidade Federal de Minas Gerais (UFMG)
}

\section{ఠ \\ OPEN ACCESS \\ EDITADO POR \\ - Andre Vinicius Lopes Coneglian (UFMG) \\ - Maria Helena de Moura Neves (UNESP) \\ - Lachlan Mackenzie (VUA) \\ AVALIADO POR \\ - Juliano Antonio (UEM) \\ - Andre Vinicius Lopes Coneglian (UFMG) \\ DATAS \\ - Recebido: 19/11/2020 \\ - Aceito: 24/11/2020 \\ - Publicado: 17/12/2020 \\ COMO CITAR \\ Pagano, A. S. (2020) \\ Modelagem da linguagem e do contexto na teoria sistêmico- funcional. Revista da Abralin, v. 19, n. 3, p. 25-49, 2020.}

\section{RESUMO}

Este artigo tem como objetivo apresentar a arquitetura sistêmico-funcional hallidayana, enfocando o modelo de contexto proposto pela teoria e incorporando suas atualizações nas últimas décadas. A apresentação tem como ponto de partida os pressupostos sobre os quais se baseia a teoria, passando, subsequentemente, a introduzir as dimensões de organização da linguagem propostas pelo arcabouço hallidayano, a saber, as dimensões globais de estratificação, instanciação e metafunção e as dimensões locais de estrutura e sistema. Uma breve apresentação é feita dos conceitos teóricos e descritivos, juntamente com os respectivos termos que os nomeiam, e exemplos são fornecidos para ilustrar a análise textual possibilitada pela abordagem. O fenômeno denominado metáfora gramatical, postulado pela teoria, é explicado no escopo da arquitetura sistêmico-funcional e relacionado com as variáveis contextuais que configuram registros e tipos de texto. $\mathrm{O}$ artigo conclui com uma síntese dos principais pontos que justificam o potencial de aplicação da teoria, fundamentado na adoção das perspectivas sistêmica e funcional para explicar a linguagem em uso.

\section{ABSTRACT}

This article aims to outline Halliday's systemic-functional architecture, focusing on the model of context developed by systemicists, including updates made in the last decades. The article first presents the assumptions upon which the theory rests, subsequently introducing the dimensions of language organization proposed within the hallidayan framework, namely the global dimensions of stratification, instantiation and metafunction, and the local dimensions of structure and system. Theoretical and descriptive concepts are briefly presented together with the terms used in 


\section{REVISTA DA ABRALIN}

the theory to name them, and examples are provided to illustrate systemic-functional text analysis. The phenomenon of grammatical metaphor posited by the theory is explained within the systemic-functional architecture and related to the contextual variables that configure registers and text-types. The article concludes with a synthesis of the main features that account for the appliable nature of the theory, bearing on the adoption of a systemic and a functional perspective to explain language in use.

\section{PALAVRAS-CHAVE}

Teoria sistêmico-funcional. Contexto. Metáfora gramatical.

\section{KEYWORDS}

Systemic-functional theory. Context. Grammatical metaphor.

\section{Introdução}

The value of a theory lies in the use that can be made of it.

M. A. K. Halliday, 1985.

Em sua comparação de três abordagens ao estudo da linguagem, agrupadas como sendo representativas do funcionalismo -- a Gramática Funcional (DIK, 1997), a Gramática de Papel e Referência (van VALIN, 2000), e a Gramática Sistêmico-Funcional (HALLIDAY, 1985; HALLIDAY; MATTHIESSEN, 2004, 2014) --, Christopher Butler (2003) destaca esta última como sendo, das três, a abordagem mais orientada ao texto e a única que desenvolve um modelo de contexto, com especificação de variáveis e geração de hipóteses que permitem explicar relações sistemáticas entre situações típicas de uso da linguagem e o tipo de linguagem nelas produzido. Um destaque adicional da Gramática Sistêmico-Funcional é, segundo Butler, seu desenvolvimento orientado para ser aplicada e gerar aplicações, dimensão, para Halliday, constitutiva da tarefa do linguista, a quem cabe, simultaneamente, desenvolver sua teoria e utilizá-la para explicar como a linguagem funciona na nossa sociedade.

As duas características destacadas por Butler representam, de fato, aspectos que a própria abordagem hallidayana ressalta. Seu escopo abrangente é evidenciado pela sua autodenominação como "teoria sistêmico-funcional" e "linguística sistêmico-funcional", reservando a designação "gramática" para um dos níveis da estratificação da linguagem por ela postulada. À sua abrangência soma-se, também, sua autoqualificação como teoria appliable, atributo que Halliday escolhe em oposição a applied (aplicado) e applicable (aplicável) e define como propriedade de possuir potencial de aplicação. Assim, transcendendo a distinção disciplinar linguística - linguística aplicada, a Teoria Sistêmico-Funcional é 


\title{
REVISTA DA ABRALIN
}

appliable por oferecer um arcabouço potencialmente passível de responder às necessidades de gerar e interpretar linguagem em uso, sem necessariamente ser concebida para atender uma aplicação em particular (HALLIDAY, 2013).

Tendo em vista os destaques feitos por Butler sobre o caráter diferencial da teoria hallidayana no âmbito do funcionalismo, este artigo se propõe a apresentar os principais componentes de sua arquitetura, situando o estrato da gramática no modelo de contexto proposto pela teoria, conforme suas atualizações na última década. Após uma breve apresentação dos pressupostos sobre os quais se baseia a teoria, são delineadas as dimensões de organização da linguagem propostas pelo arcabouço hallidayano. Conceitos teóricos e descritivos são apresentados com seus respectivos termos e exemplos ilustram a análise textual possibilitada pela abordagem. O fenômeno denominado metáfora gramatical, postulado pela teoria, é explicado no escopo da arquitetura sistêmico-funcional e relacionado com as variáveis contextuais que configuram registros e tipos de texto. Por último, o artigo sintetiza, nas suas considerações finais, os principais argumentos que embasam o potencial de aplicação da teoria, os quais dizem respeito às perspectivas sistêmica e funcional adotadas para explicar a linguagem em uso.

\section{Linguagem e realidade}

\author{
Meanings are not stored and lined up somewhere else, either inside us \\ in the mind or outside us in the real world, waiting to be meant; \\ they are brought into being in the shape of language.
} M. A. K. Halliday, 2013.

A teoria sistêmico-funcional (TSF) começou a ser desenvolvida por M. A. K. Halliday nas décadas de 1950 - 1960 e encontra-se, desde então, em contínua expansão. Trata-se, como já dito, de uma teoria robusta e abrangente, que se autoreconhece como sendo "extravagant", nas palavras de seu idealizador (HALLIDAY, 2005, p.229), no sentido de não ser comedida e não procurar reduzir a complexidade dos fenômenos que estuda, em prol da simplificação.

O principal pressuposto da linguística sistêmico-funcional, que Halliday compartilha com os autores que ele próprio nomeia seus precursores - John Firth, Louis Hjemslev, Edward Sapir e Benjamin Whorf -, diz respeito ao papel da linguagem na constituição da realidade humana. A linguagem não "reflete" a realidade; ela é o próprio agente de sua construção (HALLIDAY, 2003, p.145): 


\section{REVISTA DA ABRALIN}

As categorias e conceitos da nossa existência material não constituem algo "dado", anterior à sua expressão na linguagem. São construídos pela linguagem, na interseção do material e do simbólico [...] a gramática cria o potencial dentro do qual podemos agir e encenar nossa existência na cultura. ${ }^{1}$

Não há para a TSF, como pode ser depreendido da citação acima, dois domínios de cognição: dentro e fora da linguagem. Assim, o que em outras abordagens é tratado de forma separada da linguagem, como inferências ou conhecimento extraído do conhecimento de mundo, na TSF é subsumido num só fenômeno: o significado, que é ativamente construído em e pela linguagem.

O caráter funcional da teoria, representado no seu nome, está vinculado ao papel ativo da linguagem na construção da realidade graças à sua capacidade de gerar significado através do processo de SEMOGÊNESE (SEMOGENESIS) ${ }^{2}$. Esta se desenvolve ao longo de três escalas temporais: ONTOGÊNESE (ONTOGENESIS) ou desenvolvimento da capacidade da linguagem para gerar significados durante o crescimento do falante, de criança a adulto; FILOGÊNESE (PHYLOGENESIS) ou desenvolvimento ao longo da evolução da espécie humana; e LOGOGÊNESE (LOGOGENESIS) ou desenvolvimento ao longo da instanciação de significados no texto.

No desenvolvimento ontogênico da linguagem (da criança ao adulto), macrofunções, ou METAFUnÇõES (METAFUNCTIONS), como Halliday as denomina, vão delineando-se e, graças à gramática, se combinam para gerar enunciados que atendem às necessidades primordiais do falante, quais sejam, construir sua experiência do mundo exterior e do mundo interior da sua consciência e encenar relações sociais através das quais pode estabelecer e afirmar sua identidade em sociedade. A gramática consubstancia essas duas necessidades primárias, vinculadas respectivamente às metafunções IDEACIONAL (IDEATIONAL) e INTERPESSOAL (INTERPERSONAL), através da metafunção TEXTUAL (TEXTUAL), que contribui para a geração do DISCURSO (DISCOURSE ${ }^{3}$ ) por meio da combinação dos significados ideacionais e interpessoais no fluxo da construção dos significados.

O caráter sistêmico da teoria, também representado na sua denominação, diz respeito à sua concepção da linguagem como um grande sistema composto de REDES DE SISTEMAS (SYSTEM NETWORKS) e subsistemas, nos quais se organizam PARADIGMAS (PARADIGMS) de opções disponíveis. O objetivo da teoria é explicar como são gerados significados na linguagem. Para tanto, prioriza o EIXO PARADIGMÁTICO (SISTEMA) sobre o SINTAGMÁtICO (ESTRUTURA): o significado é gerado pelo contraste sistêmico, isto é, pelo contraste entre a forma escolhida e todas as outras formas que poderiam ter sido escolhidas, mas não o foram. As formas que compõem o paradigma são consideradas AGNATAS (AGNATE) entre si e

1 No original: "The categories and concepts of our material existence are not "given" to us prior to their expression in language. Rather, they are construed by language, at the intersection of the material with the symbolic... grammar creates the potential within which we act and enact our cultural being".

2 Neste artigo são utilizados os termos teóricos e descritivos da TSF conforme traduzidos para o português brasileiro em Figueredo (2011). Os mesmos são destacados em versalete, com indicação do termo em inglês entre parênteses, na primeira instância de uso e sempre que necessário, de forma a facilitar a leitura do texto.

3 Dados os distintos usos e significados que este termo possui nos estudos linguísticos, cabe esclarecer que na TSF o termo DISCURSO (DISCOURSE) é utilizado especificamente para se referir à construção de significado no desenvolvimento logogenético do texto (cf. HALLIDAY; MATTHIESSEN, 1999). 


\section{REVISTA DA ABRALIN}

o processo de AGNAÇÃO (AGNATION) é utilizado para se examinar as relações que vinculam duas ou mais formas no escopo de um ou mais sistemas.

A linguagem é concebida pela teoria como escolhas entre OPÇÕES (CHOICE). As escolhas não são aleatórias; antes, pressupõem SELEÇÕES (SELECTIONS) dentro de paradigmas de opções disponíveis, os quais podem ser mapeados de acordo com as diferentes dimensões de organização da linguagem postuladas pela teoria, descritas a seguir.

\section{Arquitetura sistêmico-funcional}

Language is complex - and the complexity of it is real; it is not something imposed upon it by linguists.

M. A. K. Halliday, 2005.

Para a TSF, a linguagem está organizada de acordo com três dimensões globais - ESTRATIFICAÇÃO (STRATIFICATION), INSTANCIAÇÃO (INSTANTIATION) e METAFUNÇÃO (METAFUNCTION). Há ainda duas dimensões locais - ESTRUTURA (STRUCTURE) e SISTEMA (SYSTEM). A FIGURA 1 mostra uma representação das dimensões todas e sua inter-relação.

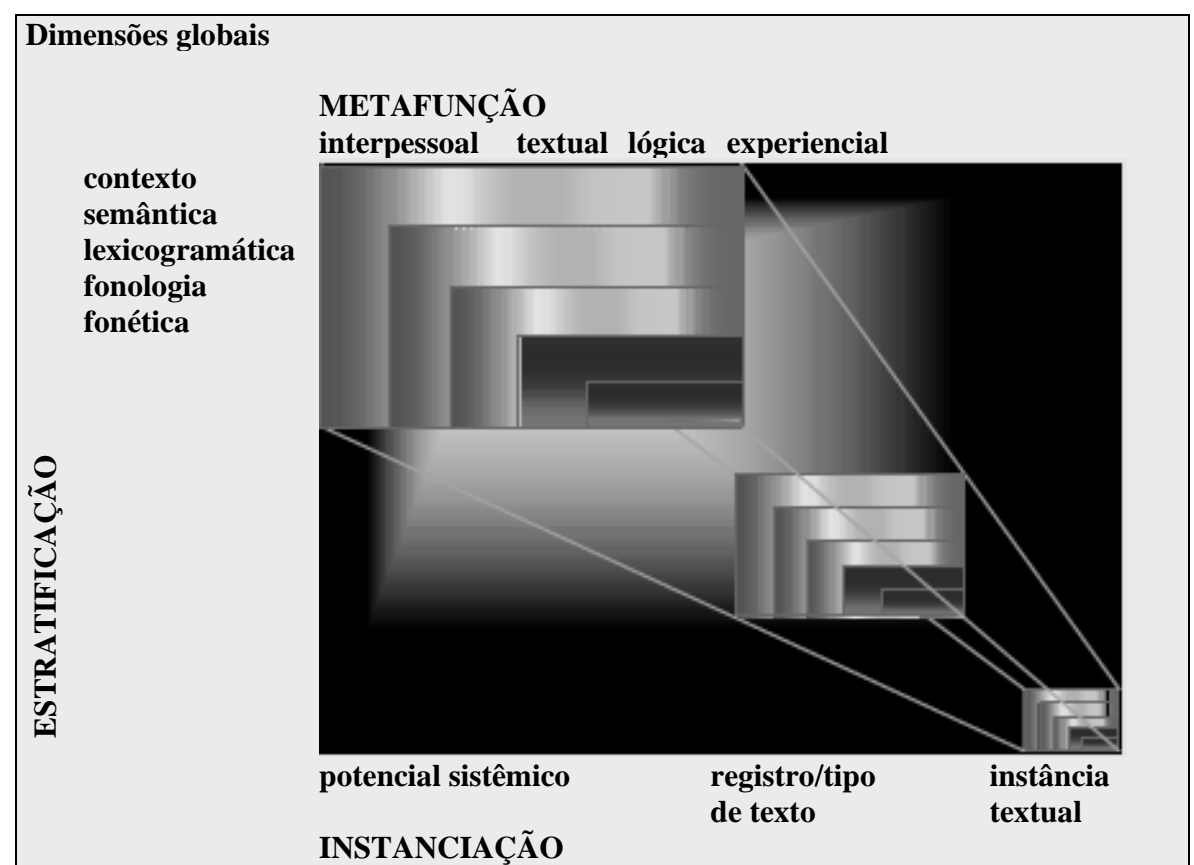

FIGURA 1 - Contínuo da instanciação como dimensão global de organização da linguagem e sua articulação com a 


\section{REVISTA DA ABRALIN}

ESTRATIFICAÇão refere-se a domínios de abstração simbólica relacionados pelo princípio de REALIZAÇÃO (REALIZATION). A linguagem é um sistema semiótico estratificado composto por dois planos inter-relacionados: CONTEÚDO (CONTENT) e EXPRESSÃO (EXPRESSION). No plano do CONTEÚDO, o estrato da SEMÂNTICA é realizado pelo estrato da GRAMATICA, e no plano da EXPRESSÃO, o estrato da FONOLOGIA/GRAFOLOGIA é realizado pelo estrato da FONÉTICA/GRAFÉTICA. Os estratos do plano do CONTEÚDO (SEMÂNTICA e GRAMATICA) são realizados pelos estratos do plano da EXPRESSÃo (FONOLOGIA/GRAFOLOGIA e FONÉTICA/GRAFÉTICA).

Diferentemente de outras teorias, a TSF concebe a GRAMÁTICA como estrato que compreende tanto a gramática como o léxico e o denomina de LEXICOGRAMÁtica (LEXICOGRAMMAR). O léxico é o polo mais DELICADO (DELICATE) da gramática, no sentido de ser decorrente de seleções em sistemas gramaticais, que por subespecificação progressiva atingem um ponto em que as opções passam a ser lexicais.

O estrato da SEMÂNTICA também é modelado de forma diferenciada na TSF. Trata-se de um estrato-chave por constituir, como explica Matthiessen (1993), "o nível de passagem para o conTEXTO (CONTEXT)" e "o ponto de acesso ao sistema onde o CONTEXTO pode ser apreendido semanticamente". Por ser um nível de passagem, cabe à SEMÂNTICA dar conta das múltiplas demandas que fazemos da linguagem, as quais exercem pressão sobre o sistema, o que leva ao surgimento de múltiplos sistemas semânticos específicos para cada tipo de situação, sistemas estes que são modelados por meio do conceito de REGISTRO (REGISTER). Para a TSF, a SEMÂNTICA é polissistêmica. Assim, à geração do significado por parte do grande sISTEMA soma-se o significado gerado pela variação no sistema, ou seja, em e pelos REGISTROS.

A TSF possui também uma visão funcional da SEMÂNTICA. Diferentemente das teorias da semântica formal e da semântica cognitiva, que explicam o significado em relação a um modelo do mundo material ou a um modelo mental, a TSF, como foi dito, explica o significado numa visão sociossemiótica, como sendo gerado em e pela linguagem no seu contexto de uso. Também, diferentemente da semântica formal e cognitiva, que privilegiam o significado representacional (IDEACIONAL), deixando significados INTERPESSOAIS e TEXTUAIS por conta da pragmática, a SEMÂNTICA na TSF contempla, de forma conjunta, os três tipos de significado - IDEACIONAL/REPRESENTACIONAL, INTERPESSOAL e TEXTUAL -, que serão detalhados mais adiante.

No que diz respeito ao CONTEXTO, este é modelado pela TSF em dois níveis de abstração denominados CONTEXTo DE CUltura (CONTEXT OF CULTURE) e CONTEXTO DE SITUAÇ̃̃o (CONTEXT OF SITUATION). O CONTEXTO DE CULTURA é o conjunto de todos os aspectos da cultura relevantes para a produção da linguagem. No escopo do CONTEXTO DE CULTURA, o CONTEXTO DE SITUAÇÃO são os aspectos relevantes para a produção de uma instância linguística numa dada SITUAÇão (SITUATION). Enquanto termo técnico, SITUAÇ̃̃o se refere a uma unidade contextual. Ao estudar uma instância linguística, observamos as variáveis do contexto em que essa instância está imbricada, isto é, seu CONTEXTO DE SITUAÇÃo. Toda

4 No original: "Semantics is the linguistic inter-level to context; it is the way into the linguistic system where context can be semanticized". (MATTHIESSEN, 1993, p. 227) 


\section{REVISTA DA ABRALIN}

SITUAÇãO está vinculada a um tipo de situação, por sua vez imbricado numa INSTITUIÇãO, parte do CONTEXTO DE CULTURA.

A TSF modela a linguagem simultaneamente sob a perspectiva de (i) a INSTÂNCIA individual (texto), (ii) o REGISTRO (TIPO DE TEXTO) e (iii) o SISTEMA como um todo, o que possibilita explicar toda e qualquer INSTÂNCIA. Não há instâncias "agramaticais" ou "exceções a regras"; toda instância de linguagem é passível de ser explicada em termos de sua maior ou menor probabilidade de ocorrência de acordo com os parâmetros de instanciação examinados.

INSTANCIAÇÃo é a segunda dimensão global de organização da linguagem, além da dimensão da ESTRATIFICAÇ̃̃O. A TSF modela a linguagem como sistema semiótico de ordem superior imbricado no CONTEXTO, também modelado como sistema semiótico de ordem superior. Ambos são mapeados e correlacionados ao longo de um CONTínUO (CLINE) chamado de CONTÍNUO DA INSTANCIAÇÃO (CLINE OF INSTANTIATION), como o QUADRO 1, reproduzido e traduzido de Matthiessen, Teruya e Lam (2010, p.123), mostra:

\begin{tabular}{lllll}
\hline & Potencial & Subpotencial & Tipo de instância & Instância \\
\hline Contexto & $\begin{array}{l}\text { contexto de cultura } \\
\text { (potencial cultural) }\end{array}$ & instituições & tipos de situação & $\begin{array}{l}\text { contextos de } \\
\text { situação }\end{array}$ \\
& $\begin{array}{l}\text { sistema linguístico } \\
\text { (potencial de } \\
\text { Linguagem }\end{array}$ & registro & tipos de texto & $\begin{array}{l}\text { textos (atos } \\
\text { de } \\
\text { significado) }\end{array}$ \\
& & & & \\
\hline
\end{tabular}

QUADRO 1 - Contínuo da instanciação no contexto e na linguagem Fonte: Adaptado de Matthiessen, Teruya e Lam (2010, p. 123)

Como vemos no QUADRO 1, no contínuo da instanciação, são correlacionados pontos de generalização ao longo dos sistemas do CONTEXTO e da LINGUAGEM: INSTÂNCIAS (INSTANCES) em particular (textos) podem ser agrupados por serem representativos de TIPOS DE TEXTO (TEXT TYPES), cuja instanciação está pautada por REGISTROS, que constituem o SISTEMA LINGUísTICO (LANGUAGE SYSTEM) como um todo. Com base em InSTÂNCIAS podemos examinar as variáveis contextuais da SITUAÇÃO (CONTEXT OF SITUATION), as quais caracterizam TIPOS DE SITUAÇÃO (SITUATION TYPES), que, por sua vez, estão imbricados em InSTITUiÇõEs (INSTITUTIONS), que formam o POTENCIAL DA CULTURA (CULTURAL POTENTIAL).

No contínuo da instanciação do sistema linguístico, REGISTRO é um ponto intermediário entre o polo do POTENCIAL e a INSTÂNCIA. Trata-se de uma variação linguística, uma subespecificação do sistema global. Diz respeito a frequências de seleções em redes de sistemas linguísticos feitas para a geração de TIPOS DE TEXTOS, cuja INSTANCIAÇÃO é determinada por valores contextuais relativos ao CAMPO (FIELD) ou tipo de ação social; às relações entre os participantes da interação ou SINTONIA (TENOR); e à organização simbólica da mensagem ou MODO (MODE). O REGISTRO é correlacionado, no CONTíNUO DO CONTEXTO, com as INSTITUIÇÕES enquanto sistemas de significados dentro do CONTEXTO DE CULTURA. As INSTITUIÇÕES semióticas configuram as instituições sociais. 


\section{REVISTA DA ABRALIN}

Toda geração de linguagem (INSTANCIAÇÃO) envolve uma subespecificação do sistema linguístico, um REGISTRO. Os REGISTROS podem ser examinados em diferentes níveis de DELICADEZA, observando-se famílias de registros, subfamílias ou bem um registro em particular. Como dissemos, os REGISTROS estão relacionados com as INSTITUIÇÕES. Assim como os REGISTROS são modelados como generalizações de TIPOS DE TEXTO, as INSTITUIÇÕES são modeladas como generalizações de TIPOS DE SITUAÇÃO.

As configurações de REGISTRO, como dito acima, são definidas pelas variáveis de CAMPO (FIELD), SINTONIA (TENOR) e MODO (MODE). Estas estão listadas no QUADRO 2.

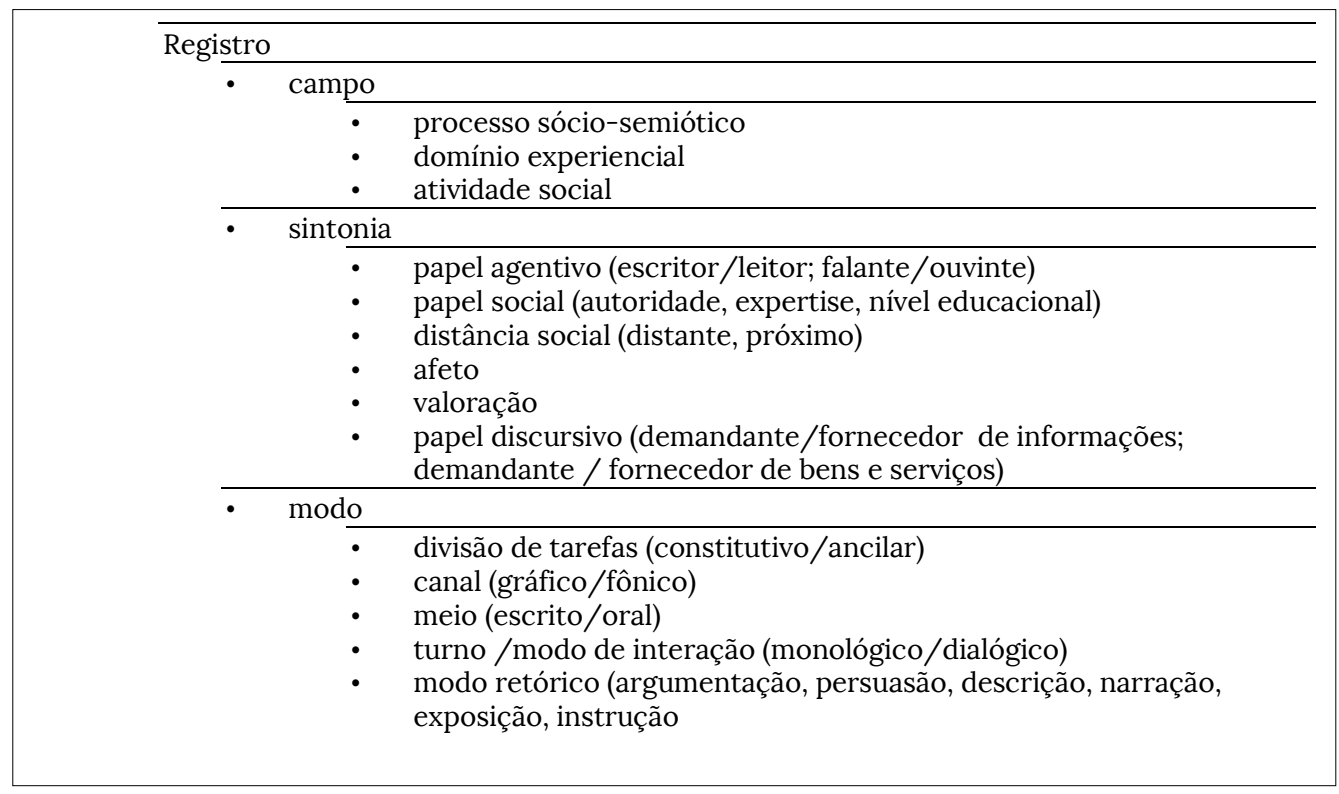

QUADRO 2 - Variáveis do contexto de situação e respectivas subdimensões Fonte: Elaborado pelo autora.

No QUADRO 2, CAMPO diz respeito à ATIVIDADE SOCIOSSEMIÓTICA da qual participam os interlocutores e ao DOMíNIO EXPERIENCIAL. SinTONIA é a variável que especifica o tipo de relação social que é estabelecida pelos interlocutores, caracterizada de acordo com: o papel institucional ou PAPEL AGENTIVO; o PAPEL SOCIAL ou relação de poder entre os falantes em termos de idade, gênero, expertise, classe social; a DISTÂNCIA SOCIAL o grau de proximidade entre os falantes (desconhecido, conhecido, familiar, íntimo); o AFETO ou envolvimento do falante numa situação de fala em termos de comportamentos cooperativos ou dissociativos; o PAPEL DISCURSIVO ou papel criado pela linguagem através do sistema de tomada de turnos; e a VALORAÇão ou atribuição de avaliação. Modo é o parâmetro que determina o papel da linguagem no contexto, caracterizado por: DIVISÃO DE TAREFAS entre a linguagem e outros sistemas semióticos; ORIENTAÇÃO da linguagem para o CAMPO (visando explicar um domínio experiencial) ou para a SINTONIA (visando regular o comportamento social); TURNO ou modo da interação (monológico ou dialógico); MEIO (escrito, falado); CANAL (fônico, gráfico, electrónico); e MODO RETÓRICO (argumentativo, descritivo, narrativo, instrucional). 


\section{REVISTA DA ABRALIN}

Pautando-se por parâmetros das variáveis de CAMPO e MODO, Matthiessen, Teruya e Lam (2010) elaboraram uma TIPOLOGIA/TOPOLOGIA de TIPOS DE TEXTOS baseada em Ure (1969). Do ponto de vista do CAMPO, a modelagem está baseada em oito ATIVIDADES SOCIOSSEMIÓTICAS que sintetizam os usos que a linguagem possibilita no CONTEXTO DE CULTURA, a saber: EXPLICAR (EXPOUNDING) ou teorizar visando a construção de conhecimento; RELATAR (REPORTING) acontecimentos; RECRIAR (RECREATING) aspectos da vida social; COMPARTILHAR (SHARING) experiências e valores; RECOMENDAR (RECOMMENDING) procedimentos e ações; HABILITAR (ENABLING) a execução de procedimentos; EXPLORAR (EXPLORING) posições e valores; e FAZER ou agir socialmente, sendo a linguagem facilitadora dessa ação. Do ponto de vista do MODO, a modelagem é feita segundo o MEIO (escrito ou falado) e o TURNO (dialógico ou monológico).

A FIGURA 2, adaptada de Matthiessen, Teruya e Lam (2010), apresenta uma representação gráfica da TIPOLOGIA/TOPOLOGIA de registros com indicação de TIPOS DE TEXTOS que são associados a cada região da topologia.

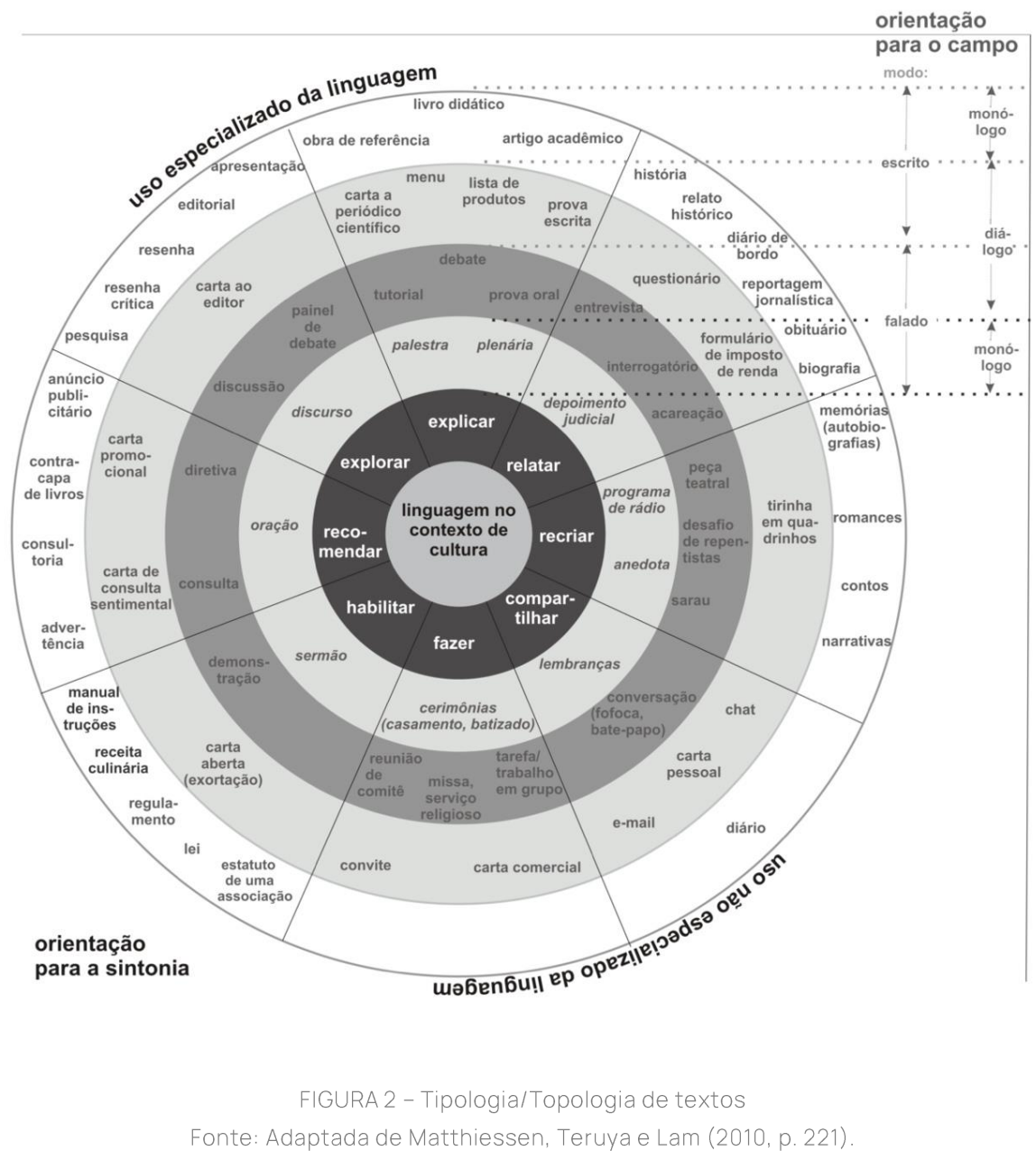

Na FIGURA 2, os círculos concêntricos estão organizados de forma a contemplar as variáveis de CAMPO E SINTONIA: no quadrante superior direito, estão concentrados os TIPOS DE TEXTO orientados para o 


\section{REVISTA DA ABRALIN}

CAMPO (FIELD) e no quadrante inferior esquerdo, encontram-se os TIPOS DE TEXTO orientados para a SINTONIA (TENOR). O quadrante superior esquerdo representa a região com maior concentração de TIPOS DE TEXTO nos quais o uso da linguagem é ESPECIALIZADO (SPECIALIZED). Já no quadrante inferior direito, estão concentrados os TIPOS DE TEXTO nos quais o uso da linguagem é NÃO ESPECIALIZADO (NON-SPECIALIZED).

As subvariáveis de MEIO e TURNO também estão contempladas na FIGURA 2: os dois círculos mais externos se referem ao MEIO escrito, e os dois círculos mais internos, ao MEIO oral; os círculos nas extremidades externa e interna contemplam o MODO monológico, estando os dois círculos entre os extremos reservados ao MODO dialógico.

A combinação das perspectivas TIPOLÓGICA e TOPOLÓGICA, princípio fundamental na TSF, justificase pela sua capacidade de apreensão do caráter intrinsicamente DIFUSO (FUZZY) da linguagem humana. Assim, a modelagem do SISTEMA pela subespecificação de categorias em REDES DE SISTEMAS (TIPOLOGIA) é complementada por uma modelagem adicional com base na analogia de sistemas, dada sua localização na SEMÂNTICA (TOPOLOGIA).

A TIPOLOGIA organiza de forma taxonômica as relações entre os distintos tipos de texto, numa escala crescente de especificidade ou DELICADEZA. Seu ponto de partida é o CONTEXTO DE CULTURA, o qual é subespecificado, em nível crescente de DELICADEZA, em ATIVIDADES SOCIOSSEMIÓTICAS, por sua vez, subespecificadas até o ponto mais DELICADO da escala: TIPOS DE TEXTOS representativos das variáveis contextuais nesse ponto do modelo. A título de exemplo, o QUADRO 3 enfoca a atividade sociossemiótica HABILITAR, e mais especificamente a subatividade CAPACITAR, representada de forma taxonômica na tipologia de registros da seguinte maneira:

\begin{tabular}{l|l|l|l}
\hline & atividade & subespecificação & tipo de texto \\
\hline \multirow{4}{*}{ contexto de cultura } & \multirow{4}{*}{ habilitar } & promover & anúncio publicitário \\
\cline { 3 - 4 } & & regular & protocolo, lei \\
\cline { 3 - 4 } & & $\begin{array}{l}\text { textos de procedimentos, } \\
\text { manual de instruções }\end{array}$ \\
\hline
\end{tabular}

QUADRO 3 - Localização tipológica da atividade sociossemiótica HABILITAR e da subespecificação CAPACITAR na TIPOLOGIA de textos

Fonte: Elaborado pelo autora.

No QUADRO 3, vemos, por exemplo, que textos de procedimentos ou manuais de instruções estão associados à atividade sociossemiótica HABILITAR (ENABLING), mais especificamente CAPACITAR (EMPOWERING).

A TOPOLOGIA organiza as relações entre as ATIVIDADES SOCIOSSEMIÓTICAS e os respectivos TIPOS DE TEXTO de forma espacial de acordo com o grau de inter-relação das configurações prototípicas. A atividade HABILITAR (ENABLING), examinada no Quadro 3 sob a perspectiva TIPOLÓGICA, está representada na FIGURA 3 de forma espacial na TOPOLOGIA de registros da seguinte maneira: 


\section{REVISTA DA ABRALIN}

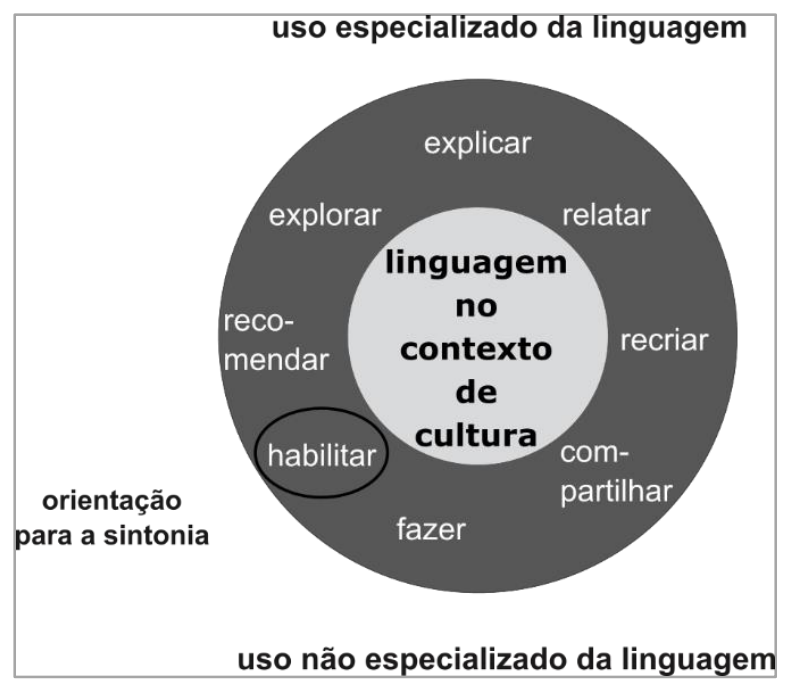

FIGURA 3 - Localização TOPOLÓGICA do processo sócio-semiótico HABILITAR na TIPOLOGIA de textos

Fonte: Elaborada pelo autora.

Como a FIGURA 3 mostra, pela sua localização TOPOLÓGICA na representação gráfica, a atividade HABILITAR (i) encontra-se num ponto intermediário na escala de especialização no uso da linguagem, entre o uso mais especializado e o não-especializado; (ii) é uma atividade orientada para a variável SINTONIA (TENOR); e (iii) encontra-se próxima das atividades RECOMENDAR e FAZER, com as quais compartilha características semânticas.

A interseção das perspectivas tipológica e topológica nos permite caracterizar, por exemplo, procedimentos e manuais de instruções como textos que funcionam no CONTEXTO DE CULTURA visando que o leitor seja capaz, ao seguir instruções ou procedimentos, de executar uma determinada atividade. A sua localização tipológica, isto é, quanto ao tipo e subtipo de ATIVIDADE SOCIOSSEMIÓTICA fornece dados sobre sua configuração prototípica de significados IDEACIONAIS, INTERPESSOAIS e TEXTUAIS e suas realizações léxico-gramaticais. Realizações prototípicas desse tipo de texto na SEMÂNTICA e na LÉXICO-GRAMATICA são, por exemplo, COMANDOs, realizados por IMPERATIVOS JUSSIVOS. Pela sua localização topológica, textos de procedimentos fazem uso de linguagem relativamente especializada, são construídos com valores específicos para a variável SINTONIA (TENOR-ORIENTED) e compartilham algumas características semânticas com tipos de textos de atividades sociossemióticas adjacentes, tais como o uso de comandos em atividades de FAZER e RECOMENDAR.

A descrição de ATIVIDADES SOCIOSSEMIÓTICAS, REGISTROS e TIPOS DE TEXTO diz respeito à dimensão da INSTANCIAÇÃO. Além da INSTANCIAÇÃo e da ESTRATIFICAÇÃO, anteriormente apresentada, a terceira dimensão global da linguagem é a METAFUnÇão. METAFUNÇ̃̃o não deve ser entendido no sentido de função ou uso da linguagem. As METAFUNÇõES da linguagem são componentes da linguagem, co-ocorrências de seleções sistêmicas, que codificam nossa experiência do mundo, nossas relações sociais e a tessitura de nossas mensagens na forma de conteúdo, especificando as opções de significação disponíveis e determinando sua realização estrutural. 


\section{REVISTA DA ABRALIN}

Como foi mencionado anteriormente, há três METAFUNÇÕES: IDEACIONAL, INTERPESSOAL e TEXTUAL, sendo que na primeira há dois componentes diferenciados: o EXPERIENCIAL (EXPERIENTIAL) e o LÓGICO (LOGICAL).

A METAFUnÇÃO IDEACIONAL constrói nossa experiência do mundo perceptível e do mundo interior da nossa consciência. Na ORDEM da ORAÇÃO, os significados ideacionais são realizados na LEXICOGRAMÁTICA pelo sistema de TRANSITIVIDADE (subcomponente EXPERIENCIAL) e pelos sistemas de TAXE e RELAÇÕES LOGICO-SEMÂNTICAS (subcomponente LÓGICO).

Os significados EXPERIENCIAIS são apresentados, tipológica- e topologicamente, na FIGURA 4, e ilustrados com orações extraídas de manuais de instruções.

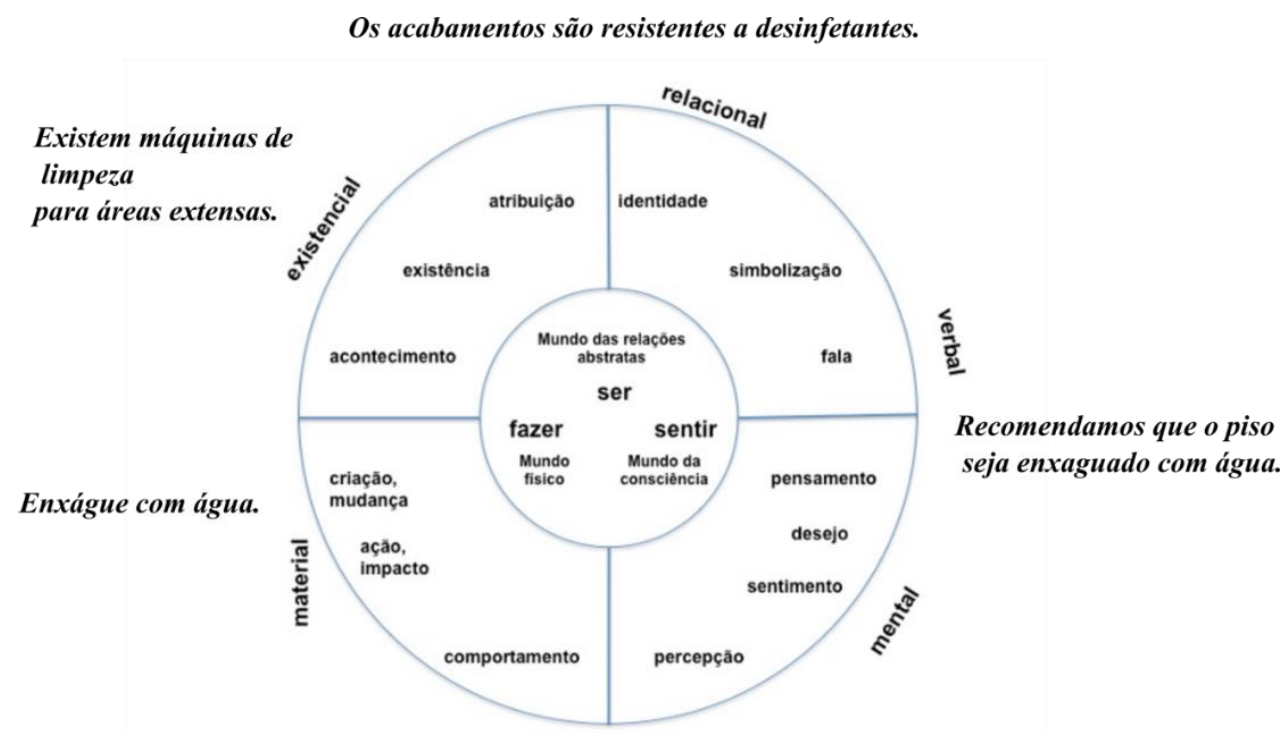

FIGURA 4 - A gramática da experiência: tipologia e topologia de processos com exemplo de orações Fonte: Elaborado pela autora com base em Halliday e Matthiessen (2014, p. 216). Exemplos da autora.

Os significados EXPERIENCIAIS são construídos na SEMÂNTICA por FIGURAS (FIGURES), que são configurações de Processos, PARTicipantes e CirCunstÂnCiAS. As FIGURAS são realizadas na LEXICOGRAMÁTICA por ORAÇÕES (CLAUSES). O espectro de significados contempla, no sentido horário na FIGURA 4, FIGURAS DE FAZER (FIGURES OF DOING), realizadas por PROCESSOS MATERIAIS (MATERIAL PROCESSES), por exemplo em "Enxágue com água pura"; FIGURAS DE ACONTECER (FIGURES OF HAPPENING), realizadas por PROCESSOS EXISTENCIAIS (EXISTENTIAL PROCESSES), como em "Existem máquinas de limpeza para áreas extensas"; FIGURAS DE SER (FIGURES OF BEING), realizadas por PROCESSOS RELACIONAIS DE IDENTIFICAÇÃO (RELATIONAL IDENTITY PROCESSES) e FIGURAS DE TER (FIGURES OF HAVING), realizadas por PROCESSOS RELACIONAIS ATRIBUTIVOS (ATTRIBUTIVE RELATIONAL PROCESSES), como em "Os acabamentos são resistentes a desinfetantes"; FIGURAS DE DIZER (FIGURES OF SAYING), realizadas por PROCESSOS VERBAIS (VERBAL PROCESSES); e FIGURAS DE EXPERIENCIAR 


\section{REVISTA DA ABRALIN}

(FIGURES OF SENSING), realizadas por PROCESSOS MENTAIS (MENTAL PROCESSES), como em "Recomendamos que o piso seja enxaguado com água" ${ }^{5}$

A METAFUNÇÃO INTERPESSOAL encena as relações que estabelecemos no convívio social e através das quais construímos nossa identidade. Na ORDEM da ORAÇÃO, os significados interpessoais são realizados na LEXICOGRAMÁTICA pelo sistema de MODO e MODALIDADE, a qual inclui MODALIZAÇÃo (graus de probabilidade) e MODULAÇão (graus de obrigatoriedade).

A METAFUNÇÃO TEXTUAL, cuja natureza é de segunda ordem, pois está orientada para uma realidade semiótica (a linguagem), cria o fluxo do DISCURSO. Na ORDEM da ORAÇÃO, os significados textuais são realizados na LEXICOGRAMÁTICA pelo sistema de TEMA.

O QUADRO 4 a seguir ilustra a análise metafuncional de uma oração extraída de um manual de instruções.

\begin{tabular}{l|l|l|l|l}
\hline ANÁLISE ESTRUTURAL & Em seguida & esfregue & a superfície & com sapólio \\
SINTAGMÁTICA \\
ANÁLISE SISTÊMICA \\
PARADIGMÁTICA
\end{tabular}

QUADRO 4 - Análise sistêmica e estrutural de uma unidade na ORDEM da ORAÇÃo Fonte: Elaborado pelo autora.

Como vemos no QUADRO 4, a METAFUnÇão TEXTUAL desempenha uma dupla tarefa: ligar a mensagem desta ORAÇÃO ao DISCURSO precedente, através de um TEMA textual continuativo ("em seguida"), e construir um ponto de partida default para a mensagem, através de um TEMA tópico, que neste caso, em se tratando de um comando, é o PROCESSO realizado por um grupo verbal ("esfregue"), cujo PARTICIPANTE (ATOR) é a pessoa da interlocução.

5 Por motivos de espaço, não são apresentados subtipos de Processo e Participante no sistema da TRANSITIVIDADE. Para uma descrição detalhada, ver Halliday e Matthiessen (2004) e Figueredo (2011). 


\section{REVISTA DA ABRALIN}

A METAFUNÇÃO INTERPESSOAL encena a relação estabelecida entre falante e ouvinte através do MODO imperativo jussivo neutro. Neste caso, o MODO é realizado pelo PREDICADOR ("esfregue") e o SUJEITO, o interlocutor, é elíptico mas é recuperado pela função SUJEITO default neste tipo de imperativo.

A METAFUNÇÃO IDEACIONAL, em seu componente LÓGICO, constrói uma FIGURA na SEMÂNTICA através de uma oração simples, finita, na LEXICOGRAMÁTICA. Há, assim, uma correlação um-a-um entre a sequência das ações esperadas do leitor e as orações, numa representação icônica típica de textos de procedimentos (cf. HALLIDAY; MATTHIESSEN, 2014, p.551).

A METAFUNÇÃO IDEACIONAL, em seu componente EXPERIENCIAL, constrói uma FIGURA DE FAZER realizada por uma oração com PROCESSO MATERIAL. Sob a perspectiva da TRANSITIVIDADE, isto é, do impacto da ação executada pelo PARTICIPANTE ATOR (ACTOR) sobre PARTICIPANTES adicionais, a ORAÇ̃̃o é transitiva e o ATOR (o executor da tarefa de esfregar) exerce uma ação com impacto sobre o PARTICIPANTE META (GOAL) (a superfície). Sob a perspectiva da ERGATIVIDADE, isto é, de quem ou o que provoca a ação, o AGENTE é o PARTICIPANTE elíptico e ATOR do PROCESSO "esfregar", que pode ser recuperado, em função de ser o PARTICIPANTE default de um PROCESSO nO MODO imperativo. O PROCESSO MATERIAL ("esfregar") é do tipo transformativo, pois envolve uma ação, na qual tanto o ATOR como a META são preexistentes e da qual se espera que haja uma transformação com impacto na META (elaboração): a superfície será esfregada.

O agenciamento pode ser testado explorando formas AGNATAS da ORAÇÃO nos sistemas de MODO e MODALIDADE, como ilustrado em (1a) e (1b).

(1a) Em seguida esfregue a superfície com sapólio

(1b) Você deve esfregar a superfície com sapólio

O MODO imperativo pode ser AGNADO no MODO declarativo com seleção de uma opção no sistema de MODALIDADE, neste caso MODULAÇÃo (obrigatoriedade), "a superfície deverá ser esfregada com sapólio (por você, pelo responsável pela limpeza)".

A CIRCUNSTÂNCIA de MEIO, mais especificamente de INSTRUMENTO (“com sapólio"), pode ser também testada através da AGNAÇÃO deste tipo de CIRCUNSTÂNCIA em uma oração MATERIAL, tendo como META o GRUPO NOMINAL que compõe a CIRCUNSTÂNCIA de MEIO e Uma ORAÇÃO NÃO FINITA de PROPÓSITO: "Utilize sapólio para esfregar a superfície".

O fenômeno da AGNAÇÃo pode ser compreendido tanto na dimensão do SISTEMA como na dimensão da ESTRUTURA, que com a INSTANCIAÇÃO, ESTRATIFICAÇÃO e METAFUNÇÃO completam os parâmetros de organização da língua.

A primeira dimensão local de organização da linguagem é o SISTEMA. O SISTEMA está pautado pelo princípio de DELICADEZA anteriormente mencionado: dada uma determinada CONDIÇÃO DE ENTRADA, temos OPÇÕES organizadas em subsistemas que podem envolver, ou não, COSSELEÇÃo e que avançam em especificidade até sua máxima distinção e associação com realizações prototípicas. No exemplo acima, temos um escolha no sistema de MODO que pode ser localizada, ao longo do EIXO PARADIGMÁTICO de OPÇÕES, em crescente nível de DELICADEZA, na FIGURA 5. 


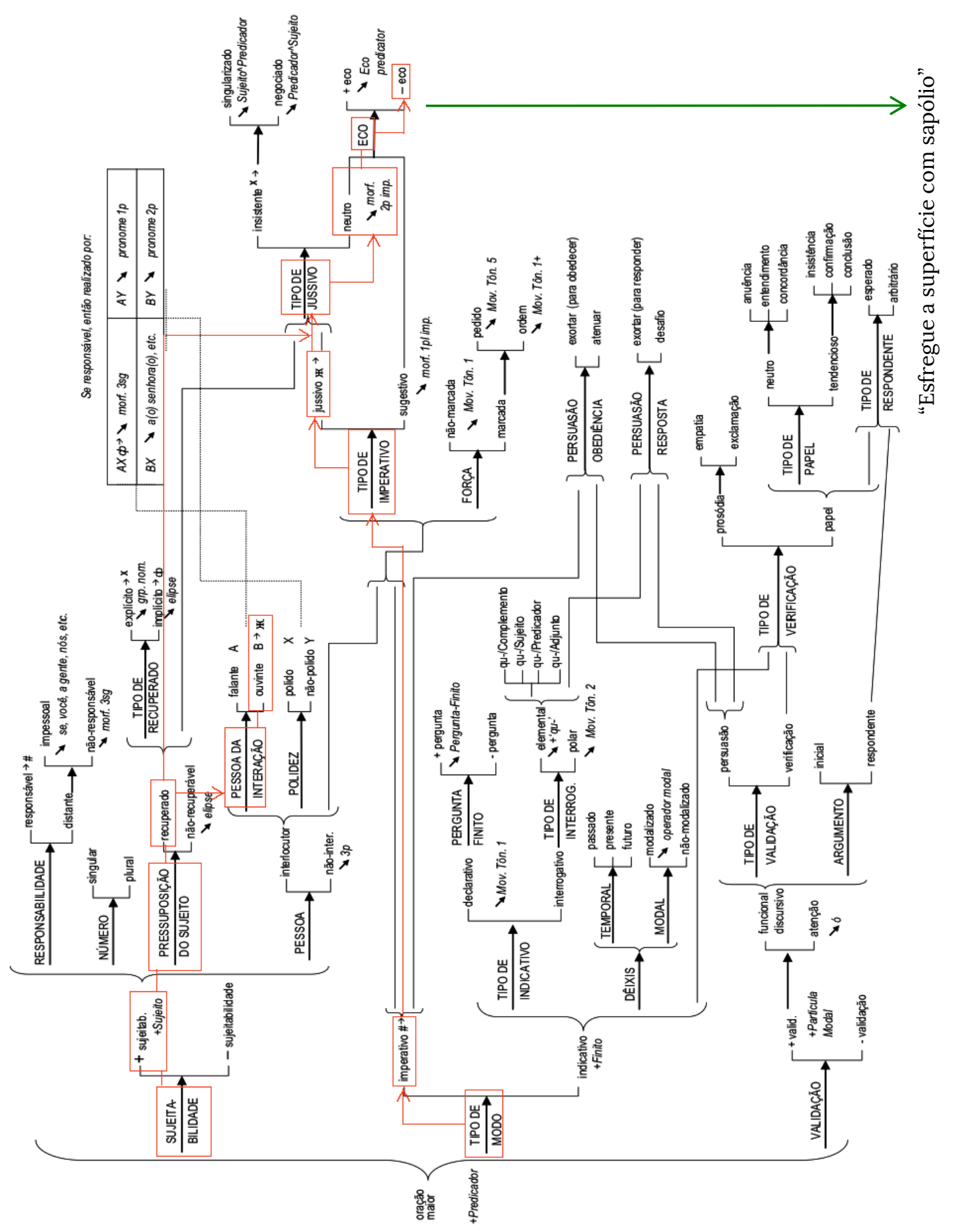

空窟 


\section{REVISTA DA ABRALIN}

Na FIGURA 5, elaborada com base em Figueredo (2011, p. 235), podemos observar, para o exemplo analisado acima ("esfregue a superfície com sapólio"), ao longo do EIXO PARADIGMÁTICO, o processo de seleção entre OPÇõES disponíveis em cada um dos subsistemas, aqui destacados em vermelho, até alcançarmos o ponto mais delicado do sistema, no qual se encontra o imperativo jussivo neutro.

A TSF teoriza quais as OPÇÕES das quais dispõe o usuário de uma língua para gerar significados, como essas OPÇÕES estão inter-relacionadas e como são REALIZADAS. A relação entre as OPÇÕES dentro de um mesmo PARADIGMA é chamada, como foi exposto, de AGNAÇÃO. Para realizar um COMANDO, como vemos na FIGURA 5 acima, o falante deve fazer ESCOLHAS no sistema de MODO, na ORDEM da ORAÇÃO, entre utilizar um imperativo jussivo ou um imperativo sugestivo, ilustrado em (2a) e (2b). No caso da ORAÇÃO em pauta, a escolha foi pelo jussivo.

(2a) Esfregue a superfície com sapólio - imperativo: jussivo: neutro

(2b) Vamos esfregar a superfície com sapólio - imperativo: sugestivo

Ainda em relação ao fenômeno da AGNAÇÃO, podemos introduzir a segunda dimensão local de organização da linguagem, a ESTRUTURA, que opera segundo o princípio da ORDEM (RANK).

No estrato da LEXICOGRAMÁTICA, na dimensão da ESTRUTURA, temos uma escala de ORDENS, pela qual unidades num nível inferior na hierarquia dão constituição a unidades em níveis superiores. Assim, na sequência decrescente da ESCALA DE ORDENS da língua escrita, a ORAÇão (CLAUSE) é constituída por GRUPOS (GROUPS), por sua vez constituídos por PALAVRAS (WORDS), as quais são constituídas por MORFEMAS (MORPHEMES). Para a ORAÇÃO 2a acima, vemos no QUADRO 5 uma análise de seus constituintes de acordo com a ESCALA DE ORDENS:

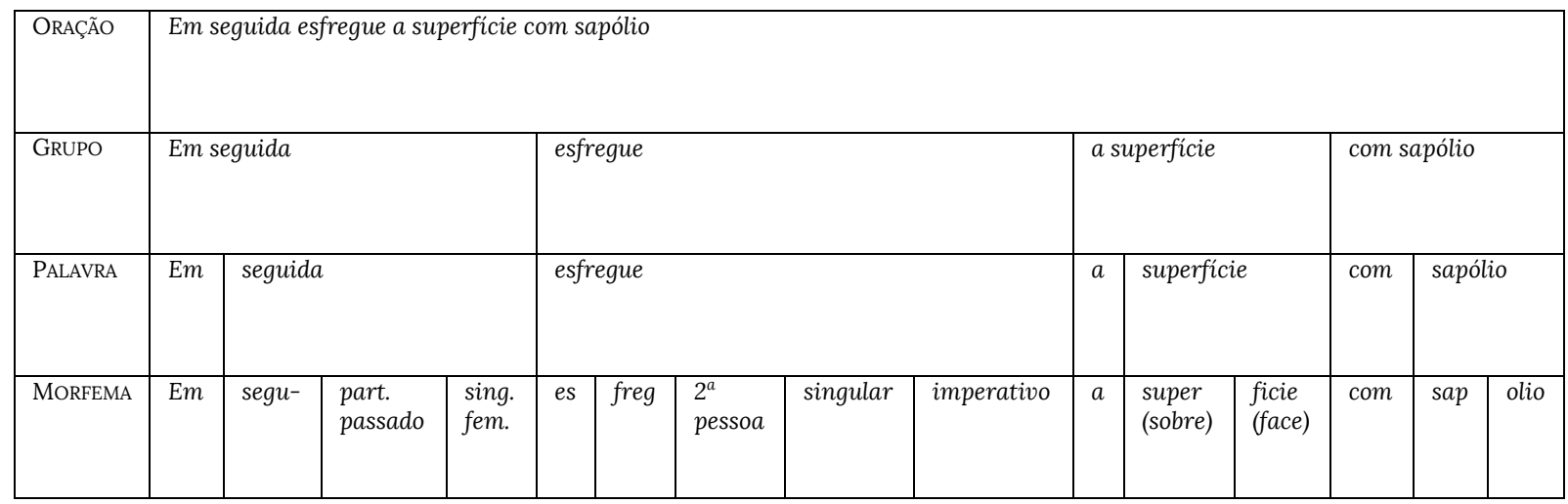

QUADRO 5 - Análise dos constituintes da ORAÇÃo na ESCALA DE ORDENS Fonte: Elaborado pelo autora.

A AGNAÇÃo pode ter lugar entre unidades, tanto da mesma ORDEM, como em ORDENS diferentes. Assim, unidades que se encontram numa posição mais inferior na ESCALA DE ORDENS podem ser AGNADAS em unidades numa posição superior. Por exemplo, a frase preposicionada "com sapólio" pode ser AGNADA com a oração não finita "utilizando sapólio" ou mesmo com uma oração finita "utilize sapólio". 


\section{REVISTA DA ABRALIN}

A dimensão da ESTRUTURA, como foi antecipado, é tributária da dimensão do SISTEMA, uma vez que a LSF concebe a linguagem como REDES DE SISTEMAS (SYSTEM NETWORKS), nas quais, dentro de um paradigma de opções disponíveis, são feitas SELEÇões (SELECTIONS) no EIXO PARADIGMÁtico. Essas SELEÇões estabelecem progressivamente um ambiente para a REALIZAÇÃO SINTAGMÁTICA Ou da ESTRUTURA nO EIXO SINTAGMÁTICO. O condicionamento da ESTRUTURA SINTAGMÁTICA pelo POTENCIAL PARADIGMÁTICO constitui o princípio AXIAL da linguagem que opera em cada estrato e seu funcionamento é fundamental para se compreender o TEXTO enquanto unidade básica de significado.

De acordo com Halliday e Martin (1993, p. 46), todo texto pode ser abordado sob uma perspectiva DINÂMICA, observando-se as relações entre suas partes ou componentes, construídas progressivamente ao longo de seu desenvolvimento, ou sob uma perspectiva SINÓPTICA, examinando-se o texto como "artefato cultural, um objeto que pode ser segmentado, interpretado, remontado e observado"6.

A abordagem DINÂMICA contempla o texto como processo em curso, processo contingente, e enfoca "o modo como INSTANCIAÇõES num determinado ponto do texto condicionam aquelas que terão lugar subsequentemente", ou, visto de um outro ângulo, "o modo como INSTANCIAÇÕES num determinado ponto do texto foram condicionadas por INSTANCIAÇÕES anteriores" (HALLIDAY; MARTIN, 1993, p. 46). Assim, privilegia o desenvolvimento do texto à medida que ele é produzido. A TSF nomeia esse parâmetro de LOGOGÊNESE textual ou INSTANCIAÇÃO do texto no tempo. Como Matthiessen (1995, p. 36) explica, a INSTANCIAÇÃo envolve, simultaneamente, seleções LÉXICO-GRAMATICAIS dentro de uma variedade de REGISTRO específica e a ATUALIZAÇÃo de diretivas de realização associadas a essas seleções. A observação pontual das instanciações nos permite identificar padrões que caracterizam fASES no DESENVOLVIMENTO LOGOGENÉTICO. Essas FASES podem ser interpretadas em relação à organização em estratos superiores, como a SEMÂNTICA, e no CONTEXTO.

Examinar o texto sob uma perspectiva DINÂMICA implica fazer uma análise léxico-gramatical progressiva, de oração em oração, observando como escolhas em determinados pontos dos subsistemas de opções condicionam escolhas posteriores. A LSF oferece um arcabouço teórico abrangente que contempla o fenômeno da LOGOGÊNESE, ao enfocar as escolhas pontuais como articuladas dentro de SISTEMAS INSTANCIAIS (MATTHIESSEN, 1995).

Dentre as metafunções da linguagem, a LSF reserva à METAFUNÇ̃̃o TEXTUAL, através dos sistemas de TEMA (na ORDEM da ORAÇ̃̃O) e da COESÃO, a tarefa de garantir a LOGOGÊNESE ou o fluxo do DISCURSO pela confluência de instanciações pontuais em nível local com articulações em nível global do texto como um todo. Também, no componente LóGico da METAFUnÇão IDEACIONAL, os sistemas de TAXE e de RELAÇÕES LÓGICO-SEMÂNTICAS realizam RELAÇÕES RETÓRICAS que no estrato da SEMÂNTICA criam significado com o DESENROLAR (UNFOLDING) do texto.

Assim, no exemplo analisado anteriormente ("Em seguida, esfregue a superfície com sapólio"), como foi apontado, a ORAÇÃO está vinculada ao DISCURSO anterior, por meio do sistema de TEMA: há um

6 No original: "a cultural artifact - as an object to be taken apart, interpreted, reassembled and observed."

7 No original: "the way in which instantiations at one point in a text put at risk those that ensue, or, to put this the other way round, the way in which instantiations at one point in a text were conditioned by earlier instantiations." 


\section{REVISTA DA ABRALIN}

TEMA textual continuativo "em seguida" e um TEMA tópico default também continuativo "você", uma vez que há uma série de comandos dirigidos ao interlocutor. No sistema de COES̃̃o, não há conjunções, mas o sistema de REFERÊNCIA permite interpretar "a mancha" e "a superfície" como retomando referentes anteriores no DISCURSO. No sistema de TAXE, temos orações finitas simples, que são interpretadas no sistema de RELAÇõES LÓGICO-SEMÂNTICAS COMO INTENSIFICAÇÃO numa sequência temporal.

Assim como a AGNAÇÃO pode abranger distintos níveis da ESCALA DE ORDENS, ela pode envolver, ainda, movimentos ou MANOBRAS (SHUNTING) entre ESTRATOS distintos. Quando as relações inter-estratos envolvem realinhamentos entre LEXICOGRAMÁTICA e SEMÂNTICA, esse fenômeno é categorizado como METÁFORA GRAMATICAL (GRAMMATICAL METAPHOR), fenômeno detalhado a seguir.

\section{A metáfora gramatical}

Realinhamentos entre LEXICOGRAMÁTICA e SEMÂNTICA são considerados manifestações de metaforização gramatical e podem estar vinculados tanto a significados IDEACIONAIS e a significados INTERPESSOAIs. Em cada caso, a TSF especifica um tipo de METÁFORA GRAMATICAL.

A METÁFORA GRAMATICAL IDEACIONAL diz respeito a

um "realinhamento" entre SEQUÊNCIAS, FIGURAS e ELEMENTOS na SEMÂNTICA e NEXOS ORACIONAIS, ORAÇÕES e GRUPOS na GRAMÁTICA. No modo CONGRUENTE de realização (...), uma SEQUÊNCIA é realizada por um nexo oracional e uma FIGURA é realizada por uma ORAÇÃO. No modo METAFÓRICO, todo o conjunto de mapeamentos parece ser rebaixado na ESCALA DE ORDENS, de modo que uma SEQUÊNCIA é realizada por uma ORAÇÃO, Uma FIGURA é realizada por um GRUPO e um ELEMENTO é realizado por uma PALAVRA. ${ }^{8}$ (HALLIDAY; MATTHIESSEN, 2004, p. 639)

Esse realinhamento pode ser mais bem compreendido a partir da FIGURA 6 a seguir, elaborada com base em uma das orações extraídas de um manual de instruções, a saber "Para este procedimento recomendamos que o ato de esfregamento seja mais intensificado".

8 No original: "a 're-mapping' between sequences, figures and elements in the semantics and clause nexuses, clauses and groups in the grammar. In the congruent mode of realizations (...), a sequence is realized by a clause nexus and a figure is realized by a clause in the metaphorical mode, the whole set of mappings seems to be shifted "downwards": a sequence is realized by a clause, a figure is realized by a group, and an element is realized by a word." 


\section{REVISTA DA ABRALIN}

\begin{tabular}{|lll|}
\hline congruente & & \multicolumn{1}{c}{ metafórico } \\
Para este procedimento & Para este procedimento & Para este procedimento \\
recomendamos que você esfregue & recomendamos que você & recomendamos que o ato \\
a superficie de forma mais & intensifique o ato de & de esfregamento seja \\
intensa & esfregamento & mais intensificado \\
\hline
\end{tabular}

FIGURA 6 - Realização com níveis variados de congruência e metaforicidade Fonte: Elaborada pelo autora.

Na FIGURA 6, temos 3 possíveis realizações para a oração projetada por "recomendamos que". Em direção ao eixo CONGRUENTE ou não metafórico, tem-se a realização de uma FIGURA DE FAZER por meio de uma oração MATERIAL, transitiva, na voz ativa, com ATOR e agenciamento explícito ("você") e com uma META também explícita ("a superfície”); ao passo que, em direção ao eixo METAFÓRICO, temos uma FIGURA DE FAZER realizada por uma oração MATERIAL, transitiva, abstrata, na voz passiva, com ATOR e agenciamento pressupostos e uma META constituída por um ENTE abstrato ("o ato de esfregamento"). A implicitude dos significados aproximam essa oração MATERIAL de uma oração RELACIONAL atributiva: "que o ato de esfregamento seja mais intenso". Na forma METAFóRICA, observamos uma condensação ou compactação do significado que na forma mais CONGRUENTE estão descompactados.

Como a FIGURA 6 também mostra, trata-se de um contínuo entre formas mais e menos CONGRUENTES, ou mais e menos METAFÓRICAS, e não de uma caracterização binária. Outras formas correlatas nesse contínuo, além das duas previstas, podem ser AGNADAS. Na FIGURA 6 acima, temos uma forma intermediária, na qual a oração MATERIAL é construída na voz ativa, com explicitação de agenciamento ("você"), nominalização do verbo lexical ("esfregar") realizador do PROCESSO MATERIAL ("o ato de esfregamento") e transformação da CIRCUNSTÂNCIA DE MODO ("com intensidade”) em verbo lexical realizador do PROCESSO MATERIAL ("intensifique").

A oração analisada ilustra os mecanismos pelos quais opera a METÁFORA GRAMATICAL IDEACIONAL, que envolve realinhamento entre SEMÂNTICA e LEXICOGRAMÁTICA com impacto nos componentes LÓGICO e EXPERIENCIAL da metafunção IDEACIONAL. Essa mesma oração nos permite ilustrar, ainda, os movimentos prototípicos da METÁFORA GRAMATICAL INTERPESSOAL. A FIGURA 7 mostra agnações relativas a significados INTERPESSOAIS que envolvem realinhamento entre SEMÂNTICA e LEXICOGRAMÁTICA:

\begin{tabular}{|l|l|}
\hline CONGRUENTE & Esfregue a superfície mais intensamente \\
& Esfregue a superfície com maior intensidade \\
Você deve esfregar a superfície com maior intensidade & Recomendamos que você esfregue a superfície com maior intensidade \\
Recomendamos que o ato de esfregamento seja mais intensificado \\
Recomenda-se que o ato de esfregamento seja mais intensificado \\
É recomendável que o ato de esfregamento seja mais intensificado \\
Recomenda-se a intensificação do esfregamento
\end{tabular}

FIGURA 7 - Exemplo de agnação de oração no contínuo de significados CONGRUENTES - METAFÓRICOS Fonte: Elaborada pelo autora. 


\section{REVISTA DA ABRALIN}

A oração em foco - "recomendamos que o ato de esfregamento seja mais intensificado" - foi extraída de um manual de instruções ou texto de procedimentos. Como foi visto, o tipo de significado prototípico construído nesse tipo de texto é o COMANDO, tipicamente realizado por uma oração no MOdO IMPERATIVO: jussivo: neutro. Quando o COMANDO seleciona MODULAÇÃo, isto é, quando ele é colocado numa escala de obrigatoriedade ("você deve, você deveria, você pode"), o MODO IMPERATIVO deixa de ser uma escolha que atenda a essa necessidade semântica de MODULAÇÃo e o MODO DECLARATIVO passa a ser selecionado. No polo mais METAFÓRICO, a MODULAÇÃo é construída de forma implícita através de uma oração RELACIONAL ("é recomendável que..."). No manual publicado, a oração é uma oração VERBAL ("recomendamos que"), na qual o agenciamento é explícito através do DIZENTE "nós". Variantes mais metafóricas em português podem construir agenciamento menos explícito através do pronome "se"9 ("recomenda-se"). Variantes menos metafóricas podem construir a MODULAÇÃo de forma mais explícita, através de um verbo modal ("você deve").

A TSF postula que há um desenvolvimento progressivo de formas congruentes a formas mais metafóricas (cf. HALLIDAY, 2002). Numa perspectiva FILOGENÉTICA, ou de evolução do sistema linguístico, observa-se o aumento de formas metafóricas à medida que a linguagem precisa atender a uma demanda por formulações de novas construções da realidade. Numa perspectiva ONTOGENÉTICA, ou de crescimento e maturação do ser humano, observa-se o desenvolvimento da linguagem da criança ao adulto, com um uso progressivo de metaforização, à medida que a criança é introduzida a novos registros, principalmente no âmbito educacional. Assim, há uma correlação sistemática entre o grau de significados compactados em um texto e a "maturidade semiótica" do produtor ou leitor do texto. Ainda, numa perspectiva LOGOGENÉTICA, ou do DESENROLAR (UNFOLDING) de um texto desde o seu início à sua conclusão, a metaforização possibilita a progressão de significados construídos ao longo do mesmo. Essas três dimensões contribuem para o desenvolvimento SEMOGENÉTICO, ou do potencial de significado da linguagem, uma vez que processos de metaforização expandem o potencial (HALLIDAY, 2003), sobretudo através da METÁFORA GRAMATICAL IDEACIONAL e do recurso da nominalização. Como Halliday (2004, Introdução, p. XX) explica, o impacto da METÁFORA GRAMATICAL não é o de acrescentar redes de sistemas ao sistema linguístico em evolução, mas o de conferir maior "densidade" aos processos de significação, uma vez que permite criar "um outro plano de realidade semiótica", construído com base em "fenômenos virtuais que existem apenas no plano semiótico"10.

A densidade do processo de significação tende a crescer exponencialmente e atinge nos registros da ciência sua realização máxima. Nesse sentido, o domínio desses registros exige, numa perspectiva ONTOGENÉTICA, a construção dos mesmos por parte do especialista. Não se trata da aprendizagem de termos técnicos, como Halliday (2004, p. 160) reiteradamente explica, mas de um desenvolvimento articulado de recursos linguísticos que permitem construir e postular uma realidade

9 Cf. Figueredo, 2011.

10 No original: " "thickening' the processes of meaning (...) "another plane of semiotic reality" (...) " "virtual" phenomena which exist solely on the semiotic plane". 


\section{REVISTA DA ABRALIN}

virtual: "aprender ciência é a mesma coisa que aprender a linguagem da ciência"11. Por isso, uma das características da linguagem da ciência é precisamente sua demanda por um usuário da língua que tenha desenvolvido sua expertise numa determinada área. Trata-se de um processo único: o especialista se forma a partir de registros que ele próprio constrói para construir sua percepção da realidade e que, por sua vez, constrói seu papel de experto na sociedade.

A rescrita da linguagem da ciência para diferentes leitores requer, muitas vezes, fazer com que formas mais metafóricas sejam reelaboradas em formas mais congruentes, o que envolve sempre a geração de significados que não são idênticos. Na linguagem científica, as formas metafóricas sempre geram, nas palavras de Halliday e Martin (1993, p.67), “algumas ambiguidades pontuais". Esse é o caso, por exemplo, quando temos GRUPOS NOMINAIS compostos por um ENTE e CLASSIFICADORES e as relações semânticas entre eles (TRANSITIVIDADE) não são explícitas ou quando são utilizados PROCESSOS RELACIONAIS cuja indeterminação permite leituras distintas das relações que se estabelecem entre PARTICIPANTES. O QUADRO 6 mostra um exemplo de ambiguidade para o leitor leigo ou em formação (crianças, por exemplo), que poderia formular, em relação aos itens destacados, perguntas como aquelas sugeridas ao lado de cada exemplo:

\begin{tabular}{l|l}
\hline EXEMPLO DE POTENCIAL AMBIGUIDADE & POSSÍVEIS INDAGAÇÕES \\
\hline $\begin{array}{l}\text { Fixação do nitrogênio em alfafa nodulada sob supressão e } \\
\text { ressuprimento de fósforo (...) }\end{array}$ & $\begin{array}{l}\text { O nitrogênio se fixa ele próprio? } \\
\text { O nitrogênio é fixado por algo ou alguém? }\end{array}$ \\
\hline
\end{tabular}

QUADRO 6 - Exemplo de ambiguidade e possiveis indagações de um leitor leigo.12 Fonte: Elaborado pelo autora.

Claramente, para a compreensão de linguagem científica como a ilustrada acima, é preciso conhecer as respostas a essas perguntas antes da leitura dos textos. Como Halliday (2004) explica, há METÁFORAS IDEACIONAIS que são essencialmente instanciais no sentido de que operam no discurso de forma a possibilitar a construção de uma argumentação lógica. Tais metáforas podem ser descompactadas ou reformuladas numa forma mais congruente. Já outras metáforas tornam-se "construtos sistêmicos", "criados para atender à formulação da teoria no longo prazo" (HALLIDAY, 2004, p. 87), o que impede sua descompactação ou formulação em formas mais congruentes. É esse o caso da terminologia de uma determinada área, como "fixação do nitrogênio". Em função disso, a leitura do especialista ou experto, como Halliday (2004, p. 48) aponta, não requer a descompactação de METÁFORAS GRAMATICAIS; já para o leigo, o texto altamente metafórico é inacessível na sua forma original, e, mesmo quando descompactado, sua especificidade ainda guarda certa ambiguidade.

11 No original: "learning science is the same thing as learning the language of science".

12 Extraído de: GOMES, F. T. et al. Metabolismo do nitrogênio em alfafa nodulada sob supressão e ressuprimento de fósforo. Rev. Bras. Fisiol. Veg., Lavras, v. 13, n. 3, 2001. 


\section{REVISTA DA ABRALIN}

De acordo com Halliday (2004, p. 93), a operação de descompactação assemelha-se a outras atividades metatextuais, como a paráfrase, a rescrita, a transformação da linguagem escrita em oral, e a tradução, no sentido de que pode haver diferentes percursos e níveis de desmetaforização ou metaforização.

A METÁFORA GRAMATICAL ilustra claramente a diversidade de exigências contextuais feitas da linguagem, as quais geram variação de REGISTRO. As demandas contextuais são tipos de situação recorrentes que se tornam parte do CONTEXTO DE CULTURA. A SEMÂNTICA deve mediar a relação entre CONTEXTO e LEXICOGRAMÁTICA, para que as configurações contextuais sejam realizadas pela variação na LEXICOGRAMÁTICA.

Inicialmente vinculada à linguagem da ciência, a METÁFORA GRAMATICAL vem ocupando registros fora desse domínio ao ponto que atualmente, como Halliday (2006, p. 211) assinala,

\footnotetext{
Qualquer texto, desde o discurso da tecnocracia e da burocracia até as revistas de TV e as alegações nutricionais nos pacotes de cereais, está de alguma forma sob o impacto dos modos de construção de significado que dão suporte ao conhecimento científico. ${ }^{13}$
}

Nesse sentido, a METÁFORA GRAMATICAL tornou-se uma forma de discurso que confere autoridade e controle a uns sobre outros, ao criar taxonomias abstratas e tecnicizar relações e processos. Assim, mesmo no texto de procedimento e instruções, "esfregar" torna-se um "ato de esfregamento", uma entidade que pode ser qualificada como "intensa" e ser passível de sofrer impacto de um outro ato, construído de forma abstrata, o "ato de intensificar".

\section{Considerações finais}

A breve descrição da arquitetura sistêmico-funcional aqui apresentada evidencia claramente o caráter diferencial da abordagem hallidayana, apontado por Butler (2003), ao ser comparada a outras teorias funcionalistas. A modelagem da linguagem e do contexto mostram a abrangência da teoria e justificam seu impacto em distintos campos disciplinares, sobretudo aqueles que demandam uma teoria do contexto e das escolhas linguísticas, como é o caso da análise textual, da análise do discurso, e diversos processos de produção multilíngue, nos quais se inclui a tradução. Esse potencial de aplicação está fundamentado, antes de mais nada, na junção das perspectivas sistêmica e funcional da teoria, que possibilitam, dada uma determinada INSTÂNCIA linguística, examiná-la simultaneamente nos respectivos loci do sistema linguístico, nos quais seleções foram feitas para gerar essa INSTÂNCIA.

Na arquitetura da TSF, toda INSTÂNCIA pode ser examinada em relação:

13 No original: "Every text, from the discourses of technocracy and bureaucracy to the television magazine and the blurb on the back of the cereal packets, is in some way affected by the modes of meaning that evolved as the scaffolding for scientific knowledge." 


\section{REVISTA DA ABRALIN}

- aos diferentes níveis de abstração no contínuo da INSTANCIAÇão (em relação a um REGISTRO Ou o SISTEMA como um todo);

- às seleções feitas nos subsistemas dos diferentes estratos do sistema linguístico (CONTEXTO, SEMÂNTICA, LÉXICO-GRAMATICA, FONOLOGIA);

- aos significados IDEACIONAIS, INTERPESSOAIS e TEXTUAIS implicados.

Além disso, toda INSTÂNCIA pode ser estudada como:

- processo, como a SELEÇão progressiva de OPÇões PARADIGMÁtiCAS dentro de SISTEMAS e seu condicionamento sucessivo à medida que a ESTRUTURA é realizada; e/ou

- produto, como o resultado de SELEções feitas, que em conjunto fazem com que o texto tenha um dado significado.

Nesse sentido, toda instância da linguagem em uso pode ser examinada como escolha passível de ser explicada dentro de uma interpretação geral do sistema linguístico como um todo (e não como uma ocorrência aleatória ou individualizada).

Além da capacidade explanatória da teoria, destaca-se seu arcabouço, cujos princípios e categorias são aplicáveis à descrição de qualquer sistema linguístico em particular. É nesse sentido que a análise textual, como a demandada no caso da tradução e outros processos de produção multilíngue, se vê potencializada pela TSF, uma vez que descrições linguísticas pautadas por um arcabouço teórico comum possibilitam estabelecer parâmetros de comparabilidade entre as línguas nos diferentes ambientes de produção multilíngue.

As múltiplas dimensões temporais de desenvolvimento da linguagem previstas pela TSF - ONTOGÊNESE, FILOGÊNESE, LOGOGÊNESE e SEMOGÊNESE - permitem observar o desenvolvimento diacrônico e diatópico do significado, este último intrinsicamente vinculado à expansão da METÁFORA GRAMATICAL e seu impacto em múltiplos registros.

A arquitetura sistêmico-funcional revela-se, de fato, "extravagante" tanto na granularidade com que os processos de construção de significado são examinados, como na riqueza metafórica com a qual os processos são nomeados. Todavia, a "extravagância" da teoria, como Halliday apontou reiteradamente ao longo de toda sua carreira, não nasce de um desejo de tornar complexo aquilo que poderia ser simples, mas de dotar as descrições linguísticas da capacidade de capturar a diversidade de recursos que a linguagem nos oferece para construir e representar nossa experiência humana. 


\section{REVISTA DA ABRALIN}

\section{Agradecimentos}

Agradeço ao Conselho Nacional de Desenvolvimento Científico e Tecnológico (CNPq Processo 443653/2018-6) pelo fomento à pesquisa em que se enquadra este ensaio teórico.

\section{REFERÊNCIAS}

BUTLER, C. Structure and function; a guide to three major structural-functional theories. Parte I. Amsterdam: John Benjamins, 2003.

DIK, S. The theory of functional grammar. Berlim e Nova York: Mouton de Gruyter, 1997.

FIGUEREDO, G. Introdução ao perfil metafuncional do português brasileiro; contribuições para os estudos multilíngues. Tese (Doutorado em Linguística Aplicada) - Faculdade de Letras, Universidade Federal de Minas Gerais, Belo Horizonte, 2011.

HALLIDAY, M. A. K. An introduction to functional grammar. 1a. ed. London: Longman, 1985.

HALLIDAY, M. A. K. On grammar. London: Continuum, 2002. (The collected works of M. A. K. Halliday, v. 1).

HALLIDAY, M. A. K. On language and linguistics. London: Continuum, 2003. (The collected

works of M. A. K. Halliday, v. 3).

HALLIDAY, M. A. K. The language of science. London: Continuum, 2004. (The collected works of M. A. K. Halliday, v. 5).

HALLIDAY, M. A. K. Language in relation to fuzzy logic and intelligent computing. Computational and quantitative studies. London: Continuum, 2005. (The collected works of M. A. K. Halliday, v. 6). p. 196-212.

HALLIDAY, M. A. K. Working with meaning: towards an appliable linguistics. In: HALLIDAY, M. A. K.; WEBSTER, J. (Ed.) Halliday in the 21st century. London: Continuum, 2013. p. 35-54.

HALLIDAY, M. A. K.; MATTHIESSEN, C. An introduction to functional grammar. 3a ed. London: Edward Arnold, 2004.

HALLIDAY, M. A. K.; MATTHIESSEN, C. Halliday's introduction to functional grammar. 4a ed. London: Edward Arnold, 2014.

HALLIDAY, M. A. K; MARTIN, J. R. Writing science: literacy and discursive power. London: Falmer (Critical Perspectives on Literary and Education), 1993.

MATTHIESSEN, C. M. I. Register in the round: diversity in a unified theory of register analysis. In: GHADESSY, M. (Ed.) Register analysis: theory and practice. London: Pinter, 1993. p. 221-92.

MATTHIESSEN, C. M. I. Lexicogrammatical cartography: English systems. Tokyo: International Language Science Publishers, 1995 


\section{REVISTA DA ABRALIN}

MATTHIESSEN, CH., TERUYA, K., LAM, M. Key terms in Systemic Functional Linguistics. London: Continuum, 2010

URE, J. Practical registers (Part 1). English language teaching, n 23, 2, p. 107-114, 1969.

van VALIN Jr., R. D. A concise introduction to Role and Reference Grammar. Fluminesia, v.12, n.1-2, p. 47-78, 2000. 